\title{
English as a Global Language; Threat or Opportunity for Minority Languages?
}

\author{
Afsaneh Majidi
}

Deakin University

\section{Doi:10.5901/mjss.2013.v4n11p33}

\section{Abstract}

The fast spread of English across the world has given an omnipresent status to the language and the reason to such worldwide dominance must be sought from various perspectives. In hot debates over global spread of English an issue which remains controversial is the threat of English to other languages, particularly those of less known communities and minority languages. Minority languages are rich reflection of multiethnic cultures and societies and carry a wealth of linguistic, historical, social, cultural, and anthropological information. Since these languages are under constant threat of marginalization and extinction, any attempt to protect and revitalize them would contribute to keep the linguistic diversity for future generation. As will be discussed, the idea of English as the killer language is simplification of a more complex phenomenon. For this purpose, first roles of minority languages are reviewed, next the literature for language shift and death is investigated and three challenging issues which seem to be concerns of global spread of English are discussed, then new roles of English in global scale are explored.

\section{Introduction}

Our world is home to 7,105 living languages; among them 1,481 are in trouble and 906 are dying (Ethnologue, 2013). As statistics of The United Nations Educational, Scientific and Cultural Organization indicate, it is estimated that if nothing is done half these languages spoken today will disappear by the end of this century. Seemingly, with the extinction of unwritten and undocumented languages, humanity would lose not only a cultural wealth but also important ancestral knowledge embedded, in particular, in indigenous languages (UNESCO, 2013). Among all these languages "English" is the only language which is spoken by more people as a second language than a first language and as observed by Crystal (2003) non native speakers of English outnumber native speakers by a ratio of 3 to 1 .

Crystal (2003) states that "a language achieves a genuinely global status when it develops a special role that is recognized in every country" (p. 3). He indicates that English is not the most significant global language because it is the mother tongue in most countries, but rather it is because of the special roles English plays within countries. The socioeconomic power embedded in English language gives it a high social status and encourages people to adopt it as the language in global context. Warschauer (2000) focuses on three critical issues which contribute to spread of English; globalization, academic and employment trend, new information technology. The revolution of 'Information Technology' and its combination with peoples' everyday life promoted communication from local to international scale and did play a significant role to export English language to countries around the world. Accordingly, launch of World Wide Web, as the global medium of gaining and exchanging information, has ultimately fixed the dominance of English in the world. However, with so many social, cultural and linguistic variations in the world the metaphor of "global village" has not yet been accepted among critical sociolinguists and they believe in composition of the world as a complex web of villages (Blommaert, 2010; Jacobson, 2003). This particular approach to globalization seems promising and would have positive applications in teaching and learning English to students from various linguistics and sociocultural background.

\section{Minority Languages}

Language is a central feature of human identity and it is inextricably bound with identity and every language, as an integral part of a culture, is a rich heritage of that culture which mirrors its speakers' identity. Gumperz (1982) believes that language "not only creates identity for its speakers but also identifies their social group membership" (p. 239). Like majority languages, minority languages are one of the influential ways to keep a nation in touch with its heritage. Such languages are valuable sources of human accomplishments and on-going manifestations of human civilisation, development and originality. They are also core values of ethnic cultures and identity. Minority languages, Lesser Used languages or Small languages as defined by European Charter for Regional or Minority Languages refer to languages 
traditionally used within a given territory of a state by nationals of that state who form a group numerically smaller than the rest of the state's population (European Union, 2013). This definition though seems to be comprehensive, does not address all multiethnic societies. For example in India the minority language speakers in some of the states are more numerous than the speakers of the so-called majority languages (Sridhar \& Kachru, 2000).

Multiethnic societies are a collage of various minority languages. Edwards (2010) includes indigenous and immigrant languages in minority languages groups and maintains that categorizing minority languages regardless their geographical settings and sociopolitical issues is an unsubstantiated typology. In multiethnic societies people are socially identified by their ethnicity. In such countries, role of minority languages is not limited to means of communication; they are sources of connection and inclusion which enhance social mobility and opportunities among their speakers. Serpell's study on Zambia communities indicates that the "Zambian local languages are intimately bound up with many of the society's traditional practices, and enshrine in multiplex and subtle ways the epistemological foundations of indigenous moral values" (Serpell, 1993, p. 97). In line with Serpell's study, Makoni and Trudell made a finding which indicates that in sub-Saharan Africa language functions as one of the most obvious markers of culture (Makoni \& Trudell, 2006). Regarding the invaluable linguistic, social and cultural values embedded in languages, preserving minority languages seems necessary to maintain integrity among its speakers and avoiding loss of cultural identity. However, the critical question which arises here is that; does English with all powerful medium contributing to its dominance threaten life of minority languages? To answer this question, it is necessary to look at language death and the contributing factors.

\section{Language Death}

A language is said to be dead or extinct when no one speaks it any more. Crystal (2002) explains that languages with only one speaker are already dead languages for language is considered alive only as long as there is someone to speak it to. He refers to implicit and explicit role of in extinction of Australian indigenous language and states that "in Australia, the presence of English has, directly or indirectly, caused great linguistic devastation, with $90 \%$ of languages moribund" (p. 87). Holmes (2008), on the contrary, believes that "many of Australian indigenous languages disappeared as a direct massacre of the aboriginal people or their death from diseases introduced by Europeans" (p. 58). As an example she refers to Tasmanian indigenous language which was exterminated with the death of its speakers. Even if accepting in Australia the dominance of English killed minority languages, this cannot be the basis for generalization. There were some extinct or disappeared minority languages which had never been exposed to English but disappeared (Holmes, 2008; Crystal, 2002). As in Latin America Crystal (2002) expounds that "English is not the language which is dominant throughout Latin America: if languages are dying there, it is not through any 'fault' of English" (p. 59).

The death of a language is not a social, cultural and linguistic concern. Ecolinguistics as a new paradigm of linguistic research equals linguistic loss as a symbol of a crisis of biodiversity by putting special emphasis on indigenous languages. They maintain that a wealth of ecological information will be lost as the language is lost. This school of thought regards saving endangered languages as an important part of the larger challenge of preserving biodiversity. For example, according to Keebe (2003) loss of a language is the permanent, irrevocable loss of a certain vision of the world and is comparable to the loss of an animal or a plant.

Languages die not just for one reason but due o mixture of reasons. Draw on studies (Holmes, 2008; Crystal, 2002) there seems to be three general reasons for death of minority languages; physical damage to people (can include either massacre or epidemic), active antipathy to individual languages, globalisation and assimilation of one culture within a more dominant culture. The role of English as the dominant language cannot be traced in first and second reasons; moreover the second reason seems to be a personal choice. But the last reason, which according to Crystal (2002) is the biggest reason and encompasses range of areas, causes language shift and consequently gradual death for a minority language. In this sense it is necessary to differentiate between language death and language shift. Holmes (2008) explains difference between language shift and death maintains that "language shift generally refers to the process by which one language displaces in the linguistic repertoire of a community. A key word in this definition is "process" which implies as a series of actions, language shift happens in several steps and gradually.

\section{Language Shift}

Language shift refers to gradual displacement of one language by another. Hornberger (2010) proposes that language shift is manifested as loss in number of speakers, level of proficiency, or functional use of the language. According to Hoffman (1991) when a community does not maintain its language, but gradually adopts another one, we talk about 
language shift. Fishman (1991) explains that language shift happens in "speech communities whose native languages are threatened because their intergenerational continuity is proceeding negatively, with fewer and fewer users or uses every generation" (p. 1). As the definitions imply 'use' or 'domain' of a language is a crucial factor to maintain it. Also, language shift is always preceded by bilingualism or multilingualism. People cannot shift to a new language unless they learn (have learnt) to speak the language.

Linguists and sociolinguists discuss range of factors contributing to language shift. Holmes (2008), mentions 3 reasons; first; economic, social and political factors, second; demographic reasons and third; attitudes and values. According to Kamwangamalu (2007) several factors are responsible for language maintenance or shift, "the most important among them being generation, the numerical strength of a group in relation to other minorities and majorities, language status and language attitude, socioeconomic value, education, institutional support, and government policies" (p. 227). Batibo (1992) also attributes language shift to a number of possible causes such as economic change, size of speech community, urbanization and relative degree of language prestige. As the studies on language shift suggest among the so many different reasons contributing to the phenomenon of language shift, socioeconomic, urbanization, attitudes and values are considered as the most influential ones. However, an important issue as Kamwangamalu explains is that these factors do not operate independently of one another but interact in complex ways to cause language shift in minority languages.

\subsection{Socioeconomic Factors}

In the era of intensified globalization, mobility of people across the world has increased too. English is accepted as the language of global discourse and gaining mastery in English language promises financial security as well as social adjustment. Paulston (1988) maintains that language shift only takes place if the language being shifted to has "social prestige and economic advantage, primarily in the form of source of income" (p. 5). Like Paulston, Holmes (2008) believes that obtaining work is the most obvious economic reason for learning another language. She indicates that job seekers see the importance of learning a new language which is widely used in business. The high demand from industries for employees with English fluency has successfully encouraged job seekers to equip themselves with English and being competent in English leads to well-paid jobs too. A clear example of this category is "immigrants". When a group of different minority language communities live in a dominant context, they would have very little chance to practice their own language. This could happen both in internal and external migration. In both situations the speakers of minority languages have little chance to practice their local language and would have to shift to the dominant language; otherwise they would not be able to survive and would be isolated. Without shifting to the language of host context the risk of isolation and being isolated would increase too. Holmes (2008) explains that they (i.e. immigrants) see no reason to keep their language therefore shift to the dominant one. Moreover, in external migration the chance of practicing the local language is even more limited and the shift happens more consciously and at a faster pace. For example, the applicants who wish to work, live or study in Australia are required to pass English language proficiency test to be eligible to apply. This indicates that such applicants make a conscious choice to choose English otherwise they would not be eligible. In such cases pressure from wider society pushes them to gradually shift the language and adapt the language and culture of dominant context. The study of Borbely (2000) on the process and factors of language shift in the Romanian minority community in Hungary also confirms that one of the factors contributing to language shift is a new social, economic or political situation that greatly alerts the life of the community.

\subsection{Urbanization}

One of the most notable effects of urbanization is high degree of geographic mobility within a certain territory or community. The geographic mobility which is gained by urbanization creates opportunities for people from different language and culture or different varieties of the same language and culture to come into contact with one to another. As a result of these changes, some features of local language and culture are exchanged with wider culture and language or one culture is assimilated within a more dominant culture. This phenomenon has some negative sides too for it will lead to reduction in the number of languages spoken in the world and one possible reason could be the 'prestige' and 'usefulness' of some certain languages in the world and marginalization of some other ones (Tandefelt, 1994). A clear example of this is the status of Brazil's indigenous languages which have lost their speakers and been recognized as 'endangered' since the process of urbanization has been accelerated in different areas of Brazil (Muller, 2001). The same concerning story has happened in India; the development of urban centres in the tribal areas is one of the most important 
causes of language shift and the direct relationship between urbanization and language shift indicates that "the higher the level of urbanization in an area, the higher the degree of language shift" (Ishtiaq, 1999, p. 108).

The study of Soylemez (2004) shows that language shifts during urbanization takes place at several stages; change in accent, assimilation of culture, change in language. These stages have a consequential order and happen one after another. His study showed meaningful relation between education and urbanization; "the higher one's access to education, the more likely he or she is to undergo an advanced urbanization process" (p. 110). Therefore it seems reasonable to conclude that level of language shift can be attributed to degree of education during urbanization process. Although studies prove language shift in urbanization, this cannot be generalized to everyone who moved from rural regions to urban areas. Still there are some individual differences which play strong role and such individual characteristics might help people to maintain their first language.

\subsection{Attitudes and Values}

One of the important factors that impact on shift and maintenance of language is attitude (Holmes \& Harlow, 1991). The speakers' outlook and value system which is part of social value and system is the main determinant of language choice and influences people's choice of which language to speak and which one to abandon. Baker (1992) defines attitude as "a hypothetical construct used to explain the direction and persistence of human behaviour" (p. 10). Personal attitudes and values in language maintenance or language shift are such strong forces that can cast a shadow over all aforementioned factors. Bilinguals or multilinguals have the freedom to choose the language they want in various situations.

Crystal (2002) uses the term 'language suicide' to explain how peoples' attitudes and values toward their own language can kill that language. He argues that "people make a conscious decision to stop using a language or not to pass it on to their children" (p. 86). As can be seen in life of immigrants, those who wish to pass on their first language to next generation create more situations to expose children with the language such as holding regular meetings, reading their first language publication, and arranging cultural and religious ceremonies. In these cases living in a foreign country and presence of English as the global language not only fades their local language but also gets a powerful medium that enables them to convey cultural dynamics to the dominant context. The findings Hatoss's study on Hungarian families living in Australia suggests that attitudes to the host society as well as the home culture play a significant role in language maintenance or shift (Hatoss, 2003). The findings of her study also indicate that keeping a strong Hungarian identity is a strong factor in intergenerational language maintenance, and the development of dual identities does not necessarily lead to language shift.

\section{New Roles of English in the Era of Globalization}

As it has been pointed at the outset of the study, critical sociolinguists view globalized world as a complex web of settlements connected by material and symbolic ties (Blommaert, 2010). Such approach to the globalized world has positive outcomes particularly in educational context, as it will lead educationalists to develop methodologies which will focus on English as a medium to connect the heterogeneous structure of the world. Jacobson (2003) mentions that having an appropriate sociolinguistic knowledge of one's native language is an important tool in learning English. In case of minority speakers, such approach in teaching English minimizes the risk of cultural or linguistic imperialism.

Intensity, scale and scope of globalization which increases day by day make people learn English as a medium to compete internationally. In this view English is no more the killer language; rather it is a means of international communication which enhances cultural dynamics among speakers of different languages without threatening minority languages. Mc Kay (2002) discusses the significance of English as an International Language (EIL) and suggests that that "English is the key as an international language in a global sense in enabling countries to discuss and negotiate political, social, educational, and economic concerns" (p. 17). She emphasizes that learning English is necessary to have access for global discourses. Mc Kay's view of English as an International Language frames English as an instrument of communication and expression of culture as she mentions that in global scale English enables speakers to exchange culture and idea. House (2003) differentiates between language for communication and language for identification. She explains how English as a Lingua Franca (ELF) enables people from different language background to converse in international scale and that this role of English minimizes threat to other languages. Clyne and Sharifian (2008) state that "English as the medium of international communication empowers all rather than just a particular group of speakers" ( $p$. 8). Obviously favouring one particular variety of English as the Standard English gets threatening to minority language 
speakers' identity and defers international communication, therefore scholars emphasize on different variations of English rather than one certain type (e.g. American or British English).

New roles of English (EIL or ELF) in global scale seem promising in process of globalization. Nevertheless, actualisation of detailed components in new roles of English requires revolutionary change in language policy and practice and the main obstacle would be 'attitudinal' (Clyne \& Sharifian, 2008).

\section{Conclusion}

Every language (either minority or majority) carries a part of human culture, identity, history and civilization, thus their maintenance and revitalization is significant. The studies show that death of a language is a complicated and multi layer phenomenon which happens due to so many reasons. Among all reasons contributing to language death, socioeconomic factors, urbanization and attitudes and values are the commonly accepted reasons of languages shift. Research suggests that implementing English as either an International Language or Lingua Franca (EIL or EFL) not only provides the opportunities for social mobility and modernity but also eliminates the probability of losing the national language, which is the carrier of identity, by helping people to be identified to the whole world as they are given voices.

To keep native languages alive, it is not enough to value them; it is essential to use them. To survive language loss which is also identity loss, getting involved in international interactions and communications is required. In this sense globalized media can have a crucial role to support local languages. World Wide Web provides endless support to introduce local and minority languages interactively. Keeping written records or video records of minority languages also can help to pass it on to next generations. Educational strategies and suitable methodology to teach English increases people's awareness and provides insights about the value of their local language.

Though in recent decades with increasing number of internal and external migration language shift has been studied extensively, still we are left with some dilemmas. Studies show that immigrant languages disappear through mother-tongue shift within three generations when immigrants or their immediate descendants do not teach their nonEnglish language to the next generation (Ortman \& Stevens, 2008). This is for sure a tragic ending for human languages. If this is the story of minority languages, then all aforementioned strategies are just suggestions to postpone language shift and let minority languages live longer. None of them can stop the process forever unless speakers change attitudes about their local language.

\section{Acknowledgement}

The author would like to express her sincere appreciation to her advisor Dr. Tricia Henry (faculty of arts and education, Deakin University) for her enthusiastic guidance and advice throughout this paper. Special thanks also go to the anonymous reviewers and editors for their valuable comments and suggestions to improve the article.

\section{References}

Baker, C. (1992). Attitudes and Language. Multilingual Matters Ltd.

Batibo, H. (1992). The fate of ethnic languages in Tanzania. In M.Brenzinger (Ed), Language Death: Factual and Theoretical Explorations with Special Reference to East Africa. Mouton De Gruyter.

Blommaert, J. (2010). The Sociolinguistics of Globalization. Cambridge University Press.

Borbely, A. (2000). The Process and Factors of Language Shift and Maintenance: Sociolinguistic Research into the Romanian Minority Community in Hungary. Research Support Scheme Electronic Library. Retrieved from <http://rss.archives.ceu.hu/archive/ 00001155/01/167.pdf>

Clyne, M., \& Sharifian, F. (2008). English as an International Language: Challenges and Opportunities. Australian Review of Applied Linguistics, 31(3).

Crystal, D. (2002). Language Death. Cambridge University Press.

Crystal, D. (2003). English as a Global Language (2nd ed.). Cambridge University Press.

Edwards, J. R. (2010). Minority Languages and Group Identity: Cases and Categories. John Benjamins.

Ethnologue, (2013). Retrieved May 16, 2013, from <http://www.ethnologue.com/world>

European Union, (2013). Retrieved June 15, 2013, from <http://www.mercator-research.eu/minority-languages/facts-figures/>

Fishman, J. A. (1991). Reversing language shift: Theoretical and empirical assistance to threatened languages. Clevedon: Multilingual Matters.

Gumperz, J. (1982). Language and social identity. Cambridge University Press.

Hatoss, A. (2003). Identity formation, cross-cultural attitudes and language maintenance in the Hungarian Diaspora of 
Queensland. Paper presented at the Cultural Citizenship, Challenges of globalisation: An interdisciplinary conference. 5-7 December 2002, Melbourne, Australia.

Hoffman, C. (1991). An Introduction to Bilingualism. London: Longman.

Holmes, J. (2008). An Introduction to Sociolinguistics (3rd ed.). Pearson Longman, Harlow, England

Holmes, J., \& Harlow, R. (1991). Threads in the New Zealand Tapestry of Language. Auckland: Linguistic Society of New Zealand.

Hornberger, N. H. (2010). Language Shift and Language Revitalization. In R. Kaplan (Ed),

Oxford Handbook of Applied Linguistics. Oxford University Press.

House, J. (2003). English as a lingua franca: a threat to multilingualism? Journal of Sociolinguistics, 7 (4), 556-578.

Ishtiaq, M. (1999). Language Shifts among the Scheduled Tribes in India: A Geographical Study. MLBD series in linguistics.

Jacobson, E. (2003). Critical Sociolinguistics in the Adult ESOL Classroom. Radical Teacher, issue 68, 13-17.

Kamwangamalu, N. M. (2007). One language, multi-layered identities: English in a society in transition, South Africa. World Englishes, 26 (3), 263-275.

Keebe, D. (2003). Language Policy and Linguistic Theory. In J. Maurais \& M. Morris (Eds), Languages in a Globalising World. Cambridge University Press.

Makoni, S., \& Trudell, B. (2006). Complementary and conflicting discourses of linguistic diversity: implications for language planning. Per Linguam, 22(2), 14-28.

McKay, S. (2002). Teaching English as an International Language: Rethinking Goals and Approaches. Oxford University Press.

Muller, O. (2001). Endangered languages in town; The Urbanization of Indigenous Languages in The Brazilian Amazon. Cultural Survival Quarterly, 25(2). Retrieved May, 10, 2013, from http://www.culturalsurvival.org/publications/cultural-survivalquarterly/brazil/endangered-languages-town-urbanization-indigenous-la

Ortman, J. M., \& Stevens, G. (2008). Shift happens, but when? Inter-and Intra generational language shift among Hispanic Americans. Population Association of America 2008 Annual Meeting program, Retrieved April, 8, 2013, from http://paa2008.princeton.edu/papers/80685

Paulston, C. B. (1988). International Handbook of Bilingualism and Bilingual Education. New York: Greenwood Press.

Serpell, R. (1993). The Significance of Schooling. Cambridge University Press.

Soylemez, U. (2004). Urbanization and language shift in Turkey: the change processes at work in the transition from rural to urban settings. International Journal of the Sociology of Language, Issue 165.

Sridhar, K. K., \& Kachru, Y. (2000). Literacy, Minority Languages, and Multilingual India. Studies in the Linguistic Sciences, (30) 1.

Tandefelt, M. (1994). Urbanization and language shift. In B. Nordberg (Ed) The Sociolinguistics of Urbanization: The Case of the Nordic Countries. Walter de Gruyter, Inc.

UNESCO, (2013). Retrieved May 10, 2013, from http://www.unesco.org/new/en/culture/themes/endangered-languages/

Warschauer, M. (2000). The Changing Global Economy and the Future of English Teaching. TESOL Quarterly, 34(3), 511-535. 